\title{
Convergence on Composite Iterative Schemes for Nonexpansive Mappings in Banach Spaces
}

\author{
Jong Soo Jung \\ Department of Mathematics, Dong-A University, Busan 604-714, South Korea
}

Correspondence should be addressed to Jong Soo Jung, jungjs@mail.donga.ac.kr

Received 13 January 2008; Revised 5 April 2008; Accepted 3 May 2008

Recommended by Mohammed Khamsi

Let $E$ be a reflexive Banach space with a uniformly Gâteaux differentiable norm. Suppose that every weakly compact convex subset of $E$ has the fixed point property for nonexpansive mappings. Let $C$ be a nonempty closed convex subset of $E, f: C \rightarrow C$ a contractive mapping (or a weakly contractive mapping), and $T: C \rightarrow C$ nonexpansive mapping with the fixed point set $F(T) \neq \varnothing$. Let $\left\{x_{n}\right\}$ be generated by a new composite iterative scheme: $y_{n}=\lambda_{n} f\left(x_{n}\right)+\left(1-\lambda_{n}\right) T x_{n}, x_{n+1}=\left(1-\beta_{n}\right) y_{n}+\beta_{n} T y_{n}$, $(n \geq 0)$. It is proved that $\left\{x_{n}\right\}$ converges strongly to a point in $F(T)$, which is a solution of certain variational inequality provided that the sequence $\left\{\lambda_{n}\right\} \subset(0,1)$ satisfies $\lim _{n \rightarrow \infty} \lambda_{n}=0$ and $\sum_{n=1}^{\infty} \lambda_{n}=\infty,\left\{\beta_{n}\right\} \subset[0, a)$ for some $0<a<1$ and the sequence $\left\{x_{n}\right\}$ is asymptotically regular.

Copyright (C) 2008 Jong Soo Jung. This is an open access article distributed under the Creative Commons Attribution License, which permits unrestricted use, distribution, and reproduction in any medium, provided the original work is properly cited.

\section{Introduction}

Let $E$ be a real Banach space and let $C$ be a nonempty closed convex subset of $E$. Recall that a mapping $f: C \rightarrow C$ is a contraction on $C$ if there exists a constant $k \in(0,1)$ such that $\| f(x)-$ $f(y)\|\leq k\| x-y \|, x, y \in C$. We use $\Sigma_{C}$ to denote the collection of mappings $f$ verifying the above inequality. That is, $\Sigma_{C}=\{f: C \rightarrow C \mid f$ is a contraction with constant $k\}$. Note that each $f \in \Sigma_{C}$ has a unique fixed point in $C$.

Now let $T: C \rightarrow C$ be a nonexpansive mapping (recall that a mapping $T: C \rightarrow C$ is nonexpansive if $\|T x-T y\| \leq\|x-y\|, x, y \in C)$ and $F(T)$ denote the set of fixed points of $T$; that is, $F(T)=\{x \in C: x=T x\}$.

We consider the iterative scheme: for $T$ nonexpansive mapping, $f \in \Sigma_{C}$ and $\lambda_{n} \in(0,1)$,

$$
x_{n+1}=\lambda_{n} f\left(x_{n}\right)+\left(1-\lambda_{n}\right) T x_{n}, \quad n \geq 0 .
$$

As a special case of (1.1), the following iterative scheme:

$$
z_{n+1}=\lambda_{n} u+\left(1-\lambda_{n}\right) T z_{n}, \quad n \geq 0,
$$


where $u, z_{0} \in C$ are arbitrary (but fixed), has been investigated by many authors; see, for example, Cho et al. [1], Halpern [2], Lions [3], Reich [4, 5], Shioji and Takahashi [6], Wittmann [7], and $\mathrm{Xu}$ [8]. The authors above showed that the sequence $\left\{z_{n}\right\}$ generated by (1.2) converges strongly to a point in the fixed point set $F(T)$ under appropriate conditions on $\left\{\lambda_{n}\right\}$ in either Hilbert spaces or certain Banach spaces. Recently, many authors also considered the iterative scheme (1.2) for finite or countable families of nonexpansive mappings $\left\{T_{i}\right\}_{i \in\{1,2, \ldots, r \text { ro } \infty\}}$; see, for instance, [9-14].

The viscosity approximation method of selecting a particular fixed point of a given nonexpansive mapping in a Hilbert space was proposed by Moudafi [15] (see [16] for finding hierarchically a fixed point). In 2004, Xu [17] extended Theorem 2.2 of Moudafi [15] for the iterative scheme (1.1) to a Banach space setting using the following conditions on $\left\{\lambda_{n}\right\}$ :

(H1) $\lim _{n \rightarrow \infty} \lambda_{n}=0 ; \sum_{n=0}^{\infty} \lambda_{n}=\infty$ or, equivalently, $\prod_{n=0}^{\infty}\left(1-\lambda_{n}\right)=0$;

(H2) $\sum_{n=0}^{\infty}\left|\lambda_{n+1}-\lambda_{n}\right|<\infty$ or $\lim _{n \rightarrow \infty}\left(\lambda_{n} / \lambda_{n+1}\right)=1$.

We also refer to [18-23] for the iterative scheme (1.1) for finite of countable families of nonexpansive mappings $\left\{T_{i}\right\}_{i \in\{1,2, \ldots, r \text { or } \infty\}}$. For the iterative scheme (1.1) with generalized contractive mappings instead of contractions, see [22, 24]. We can refer to [25] for the general iteration method for finding a zero of accretive operator.

Recently, Kim and Xu [26] provided a simpler modification of Mann iterative scheme (1.3) in a uniformly smooth Banach space as follows:

$$
\begin{gathered}
x_{0}=x \in C, \\
y_{n}=\beta_{n} x_{n}+\left(1-\beta_{n}\right) T x_{n}, \\
x_{n+1}=\alpha_{n} u+\left(1-\alpha_{n}\right) y_{n},
\end{gathered}
$$

where $u \in C$ is an arbitrary (but fixed) element, and $\left\{\alpha_{n}\right\}$ and $\left\{\beta_{n}\right\}$ are two sequences in $(0,1)$. They proved that $\left\{x_{n}\right\}$ generated by (1.3) converges to a fixed point of $T$ under the control conditions:

(i) $\lim _{n \rightarrow \infty} \alpha_{n}=0, \lim _{n \rightarrow \infty} \beta_{n}=0$;

(ii) $\sum_{n=0}^{\infty} \alpha_{n}=\infty$, (or equivalently, $\prod_{n=0}^{\infty}\left(1-\alpha_{n}\right)=0$ ), $\sum_{n=0}^{\infty} \beta_{n}=\infty$;

(iii) $\sum_{n=0}^{\infty}\left|\alpha_{n+1}-\alpha_{n}\right|<\infty, \sum_{n=0}^{\infty}\left|\beta_{n+1}-\beta_{n}\right|<\infty$.

In this paper, motivated by the above-mentioned results, as the viscosity approximation method, we consider a new composite iterative scheme for nonexpansive mapping $T$ :

$$
\begin{gathered}
x_{0}=x \in C, \\
y_{n}=\lambda_{n} f\left(x_{n}\right)+\left(1-\lambda_{n}\right) T x_{n}, \\
x_{n+1}=\left(1-\beta_{n}\right) y_{n}+\beta_{n} T y_{n},
\end{gathered}
$$

where $\left\{\beta_{n}\right\},\left\{\lambda_{n}\right\} \subset(0,1)$. First, we prove the strong convergence of the sequence $\left\{x_{n}\right\}$ generated by (IS) under the suitable conditions on the control parameters $\left\{\beta_{n}\right\}$ and $\left\{\lambda_{n}\right\}$ and the asymptotic regularity on $\left\{x_{n}\right\}$ in reflexive Banach space with a uniformly Gateaux differentiable norm together with the assumption that every weakly compact convex subset of $E$ has the fixed point property for nonexpansive mappings. Moreover, we show that the strong 
limit is a solution of certain variational inequality. Next, we study the viscosity approximation with the weakly contractive mapping to a fixed point of nonexpansive mapping in the same Banach space. The main results improve and complement the corresponding results of [1$8,15,17]$. In particular, if $\beta_{n}=0$, for all $n \geq 0$, then (IS) reduces to (1.1). We point out that the iterative scheme (IS) is a new one for finding a fixed point of $T$.

\section{Preliminaries and lemmas}

Let $E$ be a real Banach space with norm $\|\cdot\|$ and let $E^{*}$ be its dual. The value of $f \in E^{*}$ at $x \in E$ will be denoted by $\langle x, f\rangle$. When $\left\{x_{n}\right\}$ is a sequence in $E$, then $x_{n} \rightarrow x$ (resp., $x_{n} \rightarrow x$ ) will denote strong (resp., weak) convergence of the sequence $\left\{x_{n}\right\}$ to $x$.

The (normalized) duality mapping $J$ from $E$ into the family of nonempty (by Hahn-Banach theorem) weak-star compact subsets of its dual $E^{*}$ is defined by

$$
J(x)=\left\{f \in E^{*}:\langle x, f\rangle=\|x\|^{2}=\|f\|^{2}\right\}
$$

for each $x \in E$ [27].

The norm of $E$ is said to be Gateaux differentiable (and $E$ is said to be smooth) if

$$
\lim _{t \rightarrow 0} \frac{\|x+t y\|-\|x\|}{t}
$$

exists for each $x, y$ in its unit sphere $U=\{x \in E:\|x\|=1\}$. The norm is said to be uniformly Gateaux differentiable if for $y \in U$, the limit is attained uniformly for $x \in U$. The space $E$ is said to have a uniformly Fréchet differentiable norm (and $E$ is said to be uniformly smooth) if the limit in (2.2) is attained uniformly for $(x, y) \in U \times U$. It is known that $E$ is smooth if and only if each duality mapping $J$ is single-valued. It is also well known that if $E$ has a uniformly Gâteaux differentiable norm, $J$ is uniformly norm to weak continuous on each bounded subset of $E$ [27].

Let $C$ be a nonempty closed convex subset of $E$. $C$ is said to have the fixed point property for nonexpansive mappings if every nonexpansive mapping of a bounded closed convex subset $D$ of $C$ has a fixed point in $D$.

Let $D$ be a subset of $C$. Then, a mapping $Q: C \rightarrow D$ is said to be a retraction from $C$ onto $D$ if $Q x=x$ for all $x \in D$. A retraction $Q: C \rightarrow D$ is said to be sunny if $Q(Q x+t(x-Q x))=Q x$ for all $x \in C$ and $t \geq 0$ with $Q x+t(x-Q x) \in C$. A subset $D$ of $C$ is said to be a sunny nonexpansive retract of $C$ if there exists a sunny nonexpansive retraction of $C$ onto $D$. In a smooth Banach space $E$, it is well known [28, page 48] that $Q$ is a sunny nonexpansive retraction from $C$ onto $D$ if and only if the following condition holds:

$$
\langle x-Q x, J(z-Q x)\rangle \leq 0, \quad x \in C, z \in D .
$$

We need the following lemmas for the proof of our main results. (Lemma 2.1 was also given by Jung and Morales [29] and Lemma 2.2 is essentially Lemma 2 of Liu [30] (also see [8]).)

Lemma 2.1. Let $X$ be a real Banach space and let $J$ be the duality mapping. Then, for any given $x, y \in$ $X$, one has

$$
\|x+y\|^{2} \leq\|x\|^{2}+2\langle y, j(x+y)\rangle
$$

for all $j(x+y) \in J(x+y)$. 
Lemma 2.2. Let $\left\{s_{n}\right\}$ be a sequence of nonnegative real numbers satisfying

$$
s_{n+1} \leq\left(1-\alpha_{n}\right) s_{n}+\alpha_{n} \gamma_{n}+\delta_{n}, \quad n \geq 0,
$$

where $\left\{\alpha_{n}\right\},\left\{\gamma_{n}\right\}$, and $\left\{\delta_{n}\right\}$ satisfy the following conditions:

(i) $\left\{\alpha_{n}\right\} \subset[0,1]$ and $\sum_{n=0}^{\infty} \alpha_{n}=\infty$ or, equivalently, $\prod_{n=0}^{\infty}\left(1-\alpha_{n}\right)=0$,

(ii) $\lim \sup _{n \rightarrow \infty} \gamma_{n} \leq 0$ or $\sum_{n=1}^{\infty} \alpha_{n} \gamma_{n}<\infty$,

(iii) $\delta_{n} \geq 0(n \geq 0), \sum_{n=0}^{\infty} \delta_{n}<\infty$.

Then, $\lim _{n \rightarrow \infty} S_{n}=0$.

Recall that a mapping $A: C \rightarrow C$ is said to be weakly contractive if

$$
\|A x-A y\| \leq\|x-y\|-\psi(\|x-y\|), \quad \forall x, y \in C,
$$

where $\psi:[0,+\infty) \rightarrow[0,+\infty)$ is a continuous and strictly increasing function such that $\psi$ is positive on $(0, \infty)$ and $\psi(0)=0$. As a special case, if $\psi(t)=(1-k) t$ for $t \in[0,+\infty)$, where $k \in(0,1)$, then the weakly contractive mapping $A$ is a contraction with constant $k$. Rhoades [31] obtained the following result for weakly contractive mapping.

Lemma 2.3 (see [31, Theorem 2]). Let $(X, d)$ be a complete metric space, and A a weakly contractive mapping on $X$. Then, A has a unique fixed point $p$ in $X$. Moreover, for $x \in X,\left\{A^{n} x\right\}$ converges strongly to $p$.

The following lemma was given in $[32,33]$.

Lemma 2.4. Let $\left\{s_{n}\right\}$ and $\left\{\gamma_{n}\right\}$ be two sequences of nonnegative real numbers and $\left\{\lambda_{n}\right\}$ a sequence of positive numbers satisfying the conditions

(i) $\sum_{n=0}^{\infty} \lambda_{n}=\infty$ or, equivalently, $\prod_{n=0}^{\infty}\left(1-\lambda_{n}\right)=0$,

(ii) $\lim _{n \rightarrow \infty}\left(\gamma_{n} / \lambda_{n}\right)=0$.

Let the recursive inequality

$$
s_{n+1} \leq s_{n}-\lambda_{n} \psi\left(s_{n}\right)+\gamma_{n}, \quad n=0,1,2, \ldots,
$$

be given where $\psi(t)$ is a continuous and strict increasing function on $[0,+\infty)$ with $\psi(0)=0$. Then, $\lim _{n \rightarrow \infty} s_{n}=0$.

Finally, the sequence $\left\{x_{n}\right\}$ in $E$ is said to be asymptotically regular if

$$
\lim _{n \rightarrow \infty}\left\|x_{n+1}-x_{n}\right\|=0
$$

\section{Main results}

First, using the asymptotic regularity, we study a strong convergence theorem for a composite iterative scheme for the nonexpansive mapping with the contractive mapping. 
For $T: C \rightarrow C$ nonexpansive and so for any $t \in(0,1)$ and $f \in \Sigma_{C}, t f+(1-t) T: C \rightarrow C$ defines a strict contraction mapping. Thus, by the Banach contraction mapping principle, there exists a unique fixed point $x_{t}^{f}$ satisfying

$$
x_{t}^{f}=t f\left(x_{t}^{f}\right)+(1-t) T x_{t}^{f} .
$$

For simplicity, we will write $x_{t}$ for $x_{t}^{f}$ provided no confusion occurs.

In 2006, the following result was given by Jung [18] (see also $\mathrm{Xu}$ [17] for the result in uniformly smooth Banach spaces).

Theorem J (see Jung [18]). Let E be a reflexive Banach space with a uniformly Gâteaux differentiable norm. Suppose that every weakly compact convex subset of $E$ has the fixed point property for nonexpansive mappings. Let $C$ be a nonempty closed convex subset of $E$ and $T$ nonexpansive mapping from $C$ into itself with $F(T) \neq \varnothing$. Then, $\left\{x_{t}\right\}$ defined by $(\mathrm{R})$ converges strongly to a point in $F(T)$. If one defines $Q: \Sigma_{C} \rightarrow F(T)$ by

$$
Q(f):=\lim _{t \rightarrow 0^{+}} x_{t}, \quad f \in \Sigma_{C},
$$

then $Q(f)$ solves a variational inequality

$$
\langle(I-f)(Q(f)), J(Q(f)-p)\rangle \leq 0, \quad f \in \Sigma_{C}, p \in F(T) .
$$

Remark 3.1. In Theorem J, if $f(x)=u \in C$ is a constant, then (3.2) becomes

$$
\langle Q(u)-u, J(Q(u)-p)\rangle \leq 0, \quad u \in C, p \in F(T) .
$$

Hence by (2.3), $Q$ reduces to the sunny nonexpansive retraction from $C$ to $F(T)$. Namely, $F(T)$ is a sunny nonexpansive retraction of $C$.

Using Theorem $\mathrm{J}$ and the asymptotic regularity on the sequence $\left\{x_{n}\right\}$, we have the following result.

Theorem 3.2. Let E be a reflexive Banach space with a uniformly Gâteaux differentiable norm. Suppose that every weakly compact convex subset of $E$ has the fixed point property for nonexpansive mappings. Let $C$ be a nonempty closed convex subset of $E$ and $T$ nonexpansive mappings from $C$ into itself with $F(T) \neq \varnothing$. Let $\left\{\beta_{n}\right\}$ and $\left\{\lambda_{n}\right\}$ be sequences in $(0,1)$ which satisfies the conditions:

(B1) $\beta_{n} \in[0, a)$ for some $0<a<1$ for all $n \geq 0$,

(C1) $\lim _{n \rightarrow \infty} \lambda_{n}=0 ; \sum_{n=0}^{\infty} \lambda_{n}=\infty$.

Let $f \in \Sigma_{C}$ and $x_{0} \in C$ be chosen arbitrarily. Let $\left\{x_{n}\right\}$ be the sequence generated by

$$
\begin{gathered}
x_{0}=x \in C, \\
y_{n}=\lambda_{n} f\left(x_{n}\right)+\left(1-\lambda_{n}\right) T x_{n}, \\
x_{n+1}=\left(1-\beta_{n}\right) y_{n}+\beta_{n} T y_{n}, \quad n \geq 0 .
\end{gathered}
$$

If $\left\{x_{n}\right\}$ is asymptotically regular, then $\left\{x_{n}\right\}$ converges strongly to $Q(f) \in F(T)$, where $Q(f)$ is the unique solution of the variational inequality

$$
\langle(I-f)(Q(f)), J(Q(f)-p)\rangle \leq 0, \quad f \in \Sigma_{C}, p \in F(T) .
$$


Proof. We notice that by Theorem J, there exists a solution $Q(f)$ of a variational inequality

$$
\langle(I-f)(Q(f)), J(Q(f)-p)\rangle \leq 0, \quad f \in \Sigma_{C}, p \in F(T) .
$$

Namely, $Q(f)=\lim _{t \rightarrow 0^{+}} x_{t}$, where $x_{t}$ is defined by $(\mathrm{R})$. We will show that $x_{n} \rightarrow Q(f)$.

We proceed with the following steps.

Step 1. We show that $\left\|x_{n}-z\right\| \leq \max \left\{\left\|x_{0}-z\right\|,(1 /(1-k))\|f(z)-z\|\right\}$ for all $n \geq 0$ and all $z \in F(T)$ and so $\left\{x_{n}\right\},\left\{y_{n}\right\},\left\{f\left(x_{n}\right)\right\},\left\{T x_{n}\right\}$, and $\left\{T y_{n}\right\}$ are bounded.

Indeed, let $z \in F(T)$. Then, we have

$$
\begin{aligned}
\left\|y_{n}-z\right\| & =\left\|\lambda_{n}\left(f\left(x_{n}\right)-z\right)+\left(1-\lambda_{n}\right)\left(T x_{n}-z\right)\right\| \\
& \leq \lambda_{n}\left\|f\left(x_{n}\right)-z\right\|+\left(1-\lambda_{n}\right)\left\|x_{n}-z\right\| \\
& \leq \lambda_{n}\left(\left\|f\left(x_{n}\right)-f(z)\right\|+\|f(z)-z\|\right)+\left(1-\lambda_{n}\right)\left\|x_{n}-z\right\| \\
& \leq \lambda_{n} k\left\|x_{n}-z\right\|+\lambda_{n}\|f(z)-z\|+\left(1-\lambda_{n}\right)\left\|x_{n}-z\right\| \\
& =\left(1-(1-k) \lambda_{n}\right)\left\|x_{n}-z\right\|+\lambda_{n}\|f(z)-z\| \\
& \leq \max \left\{\left\|x_{n}-z\right\|, \frac{1}{1-k}\|f(z)-z\|\right\}, \\
\left\|x_{n+1}-z\right\| & =\left\|\left(1-\beta_{n}\right)\left(y_{n}-z\right)+\beta_{n}\left(T y_{n}-z\right)\right\| \\
& \leq\left(1-\beta_{n}\right)\left\|y_{n}-z\right\|+\beta_{n}\left\|y_{n}-z\right\| \\
& =\left\|y_{n}-z\right\| \leq \max \left\{\left\|x_{n}-z\right\|, \frac{1}{1-k}\|f(z)-z\|\right\} .
\end{aligned}
$$

Using an induction, we obtain

$$
\left\|x_{n}-z\right\| \leq \max \left\{\left\|x_{0}-z\right\|, \frac{1}{1-k}\|f(z)-z\|\right\}
$$

for all $n \geq 0$. Hence, $\left\{x_{n}\right\}$ is bounded, and so are $\left\{y_{n}\right\},\left\{T x_{n}\right\},\left\{T y_{n}\right\}$, and $\left\{f\left(x_{n}\right)\right\}$. Moreover, it follows from condition (C1) that

$$
\left\|y_{n}-T x_{n}\right\|=\lambda_{n}\left\|f\left(x_{n}\right)-T x_{n}\right\| \longrightarrow 0 \quad(\text { as } n \longrightarrow \infty) .
$$

Step 2. We show that $\lim _{n \rightarrow \infty}\left\|x_{n+1}-y_{n}\right\|=0$ and $\lim _{n \rightarrow \infty}\left\|x_{n}-y_{n}\right\|=0$. Indeed, by the condition (B1)

$$
\begin{aligned}
\left\|x_{n+1}-y_{n}\right\| & =\beta_{n}\left\|T y_{n}-y_{n}\right\| \\
& \leq \beta_{n}\left(\left\|T y_{n}-T x_{n}\right\|+\left\|T x_{n}-y_{n}\right\|\right) \\
& \leq a\left(\left\|y_{n}-x_{n}\right\|+\left\|T x_{n}-y_{n}\right\|\right) \\
& \leq a\left(\left\|y_{n}-x_{n+1}\right\|+\left\|x_{n+1}-x_{n}\right\|+\left\|T x_{n}-y_{n}\right\|\right)
\end{aligned}
$$

which implies that

$$
\left\|x_{n+1}-y_{n}\right\| \leq \frac{a}{1-a}\left(\left\|x_{n+1}-x_{n}\right\|+\left\|T x_{n}-y_{n}\right\|\right)
$$


Jong Soo Jung

So, by asymptotic regularity of $\left\{x_{n}\right\}$ and (3.8), we have $\left\|x_{n+1}-y_{n}\right\| \rightarrow 0$, and also

$$
\left\|x_{n}-y_{n}\right\| \leq\left\|x_{n}-x_{n+1}\right\|+\left\|x_{n+1}-y_{n}\right\| \longrightarrow 0 \quad(\text { as } n \longrightarrow \infty)
$$

Step 3. We show that $\lim _{n \rightarrow \infty}\left\|y_{n}-T y_{n}\right\|=0$. By (3.8) and Step 2, we have

$$
\begin{aligned}
\left\|y_{n}-T y_{n}\right\| & \leq\left\|y_{n}-T x_{n}\right\|+\left\|T x_{n}-T y_{n}\right\| \\
& \leq\left\|y_{n}-T x_{n}\right\|+\left\|x_{n}-y_{n}\right\| \longrightarrow 0
\end{aligned}
$$

Step 4. We show that $\lim \sup _{n \rightarrow \infty}\left\langle Q(f)-f(Q(f)), J\left(Q(f)-y_{n}\right)\right\rangle \leq 0$. To prove this, let a subsequence $\left\{y_{n_{j}}\right\}$ of $\left\{y_{n}\right\}$ be such that

$$
\limsup _{n \rightarrow \infty}\left\langle Q(f)-f(Q(f)), J\left(Q(f)-y_{n}\right)\right\rangle=\lim _{j \rightarrow \infty}\left\langle Q(f)-f(Q(f)), J\left(Q(f)-y_{n_{j}}\right)\right\rangle
$$

and $y_{n_{j}} \rightarrow p$ for some $p \in E$. From Step 3, it follows that $\lim _{j \rightarrow \infty}\left\|y_{n_{j}}-T y_{n_{j}}\right\|=0$.

Now let $Q(f)=\lim _{t \rightarrow 0^{+}} x_{t}$, where $x_{t}=t f\left(x_{t}\right)+(1-t) T x_{t}$. Then, we can write

$$
x_{t}-y_{n_{j}}=t\left(f\left(x_{t}\right)-y_{n_{j}}\right)+(1-t)\left(T x_{t}-y_{n_{j}}\right) \text {. }
$$

Putting

$$
a_{j}(t)=(1-t)^{2}\left\|T y_{n_{j}}-y_{n_{j}}\right\|\left(2\left\|x_{t}-y_{n_{j}}\right\|+\left\|T y_{n_{j}}-y_{n_{j}}\right\|\right) \longrightarrow 0 \quad(j \longrightarrow \infty)
$$

by Step 3 and using Lemma 2.1, we obtain

$$
\begin{aligned}
\left\|x_{t}-y_{n_{j}}\right\|^{2} & \leq(1-t)^{2}\left\|T x_{t}-y_{n_{j}}\right\|^{2}+2 t\left\langle f\left(x_{t}\right)-y_{n_{j}}, J\left(x_{t}-y_{n_{j}}\right)\right\rangle \\
& \leq(1-t)^{2}\left(\left\|T x_{t}-T y_{n_{j}}\right\|+\left\|T y_{n_{j}}-y_{n_{j}}\right\|\right)^{2}+2 t\left\langle f\left(x_{t}\right)-x_{t}, J\left(x_{t}-y_{n_{j}}\right)\right\rangle+2 t\left\|x_{t}-y_{n_{j}}\right\|^{2} \\
& \leq(1-t)^{2}\left\|x_{t}-y_{n_{j}}\right\|^{2}+a_{j}(t)+2 t\left\langle f\left(x_{t}\right)-x_{t}, J\left(x_{t}-y_{n_{j}}\right)\right\rangle+2 t\left\|x_{t}-y_{n_{j}}\right\|^{2} .
\end{aligned}
$$

The last inequality implies

$$
\left\langle x_{t}-f\left(x_{t}\right), J\left(x_{t}-y_{n_{j}}\right)\right\rangle \leq \frac{t}{2}\left\|x_{t}-y_{n_{j}}\right\|^{2}+\frac{1}{2 t} a_{j}(t)
$$

It follows that

$$
\limsup _{j \rightarrow \infty}\left\langle x_{t}-f\left(x_{t}\right), J\left(x_{t}-y_{n_{j}}\right)\right\rangle \leq \frac{t}{2} M
$$

where $M>0$ is a constant such that $M \geq\left\|x_{t}-y_{n}\right\|^{2}$ for all $n \geq 0$ and $t \in(0,1)$. Taking the $\limsup$ as $t \rightarrow 0$ in (3.18) and noticing the fact that the two limits are interchangeable due to the fact that $J$ is uniformly continuous on bounded subsets of $E$ from the strong topology of $E$ to the weak* topology of $E^{*}$, we have

$$
\limsup _{j \rightarrow \infty}\left\langle Q(f)-f(Q(f)), J\left(Q(f)-y_{n_{j}}\right)\right\rangle \leq 0 .
$$


Indeed, letting $t \rightarrow 0$, from (3.18) we have

$$
\limsup _{t \rightarrow 0} \limsup _{j \rightarrow \infty}\left\langle x_{t}-f\left(x_{t}\right), J\left(x_{t}-y_{n_{j}}\right)\right\rangle \leq 0
$$

So, for any $\varepsilon>0$, there exists a positive number $\delta_{1}$ such that for any $t \in\left(0, \delta_{1}\right)$,

$$
\limsup _{j \rightarrow \infty}\left\langle x_{t}-f\left(x_{t}\right), J\left(x_{t}-y_{n_{j}}\right)\right\rangle \leq \frac{\varepsilon}{2}
$$

Moreover, since $x_{t} \rightarrow Q(f)$ as $t \rightarrow 0$, the set $\left\{x_{t}-y_{n_{j}}\right\}$ is bounded and the duality mapping $J$ is norm-to-weak* uniformly continuous on bounded subset of $E$, there exists $\delta_{2}>0$ such that, for any $t \in\left(0, \delta_{2}\right)$,

$$
\begin{aligned}
\mid\langle Q(f)- & \left.f(Q(f)), J\left(Q(f)-y_{n_{j}}\right)\right\rangle-\left\langle x_{t}-f\left(x_{t}\right), J\left(x_{t}-y_{n_{j}}\right)\right\rangle \mid \\
= & \mid\left\langle Q(f)-f(Q(f)), J\left(Q(f)-y_{n_{j}}\right)-J\left(x_{t}-y_{n_{j}}\right)\right\rangle \\
& +\left\langle Q(f)-f(Q(f))-\left(x_{t}-f\left(x_{t}\right)\right), J\left(x_{t}-y_{n_{j}}\right)\right\rangle \mid \\
\leq & \left|\left\langle Q(f)-f(Q(f)), J\left(x_{t}-y_{n_{j}}\right)-J\left(Q(f)-y_{n_{j}}\right)\right\rangle\right| \\
+ & \left\|Q(f)-f(Q(f))-\left(x_{t}-f\left(x_{t}\right)\right)\right\|\left\|x_{t}-y_{n_{j}}\right\|<\frac{\varepsilon}{2} .
\end{aligned}
$$

Choose $\delta=\min \left\{\delta_{1}, \delta_{2}\right\}$, we have for all $t \in(0, \delta)$ and $j \in \mathbb{N}$,

$$
\left\langle Q(f)-f(Q(f)), J\left(Q(f)-y_{n_{j}}\right)\right\rangle\left\langle\left\langle x_{t}-f\left(x_{t}\right), J\left(x_{t}-y_{n_{j}}\right)\right\rangle+\frac{\varepsilon}{2},\right.
$$

which implies that

$$
\limsup _{j \rightarrow \infty}\left\langle Q(f)-f(Q(f)), J\left(Q(f)-y_{n_{j}}\right)\right\rangle \leq \limsup _{j \rightarrow \infty}\left\langle x_{t}-f\left(x_{t}\right), J\left(x_{t}-y_{n_{j}}\right)\right\rangle+\frac{\varepsilon}{2} .
$$

Since $\lim \sup _{j \rightarrow \infty}\left\langle x_{t}-f\left(x_{t}\right), J\left(x_{t}-y_{n_{j}}\right)\right\rangle \leq \varepsilon / 2$, we have

$$
\limsup _{j \rightarrow \infty}\left\langle Q(f)-f(Q(f)), J\left(Q(f)-y_{n_{j}}\right)\right\rangle \leq \varepsilon
$$

Since $\varepsilon$ is arbitrary, we obtain that

$$
\limsup _{j \rightarrow \infty}\left\langle Q(f)-f(Q(f)), J\left(Q(f)-y_{n_{j}}\right)\right\rangle \leq 0
$$

Step 5. We show that $\lim _{n \rightarrow \infty}\left\|x_{n}-Q(f)\right\|=0$. By using (IS), we have

$$
\left\|x_{n+1}-Q(f)\right\| \leq\left\|y_{n}-Q(f)\right\|=\left\|\lambda_{n}\left(f\left(x_{n}\right)-Q(f)\right)+\left(1-\lambda_{n}\right)\left(T x_{n}-Q(f)\right)\right\|
$$


Applying Lemma 2.1, we obtain

$$
\begin{aligned}
\| x_{n+1}- & Q(f)\left\|^{2} \leq\right\| y_{n}-Q(f) \|^{2} \\
\leq & \left(1-\lambda_{n}\right)^{2}\left\|T x_{n}-Q(f)\right\|^{2}+2 \lambda_{n}\left\langle f\left(x_{n}\right)-Q(f), J\left(y_{n}-Q(f)\right)\right\rangle \\
\leq & \left(1-\lambda_{n}\right)^{2}\left\|x_{n}-Q(f)\right\|^{2}+2 \lambda_{n}\left\langle f\left(x_{n}\right)-f(Q(f)), J\left(y_{n}-Q(f)\right)\right\rangle \\
& +2 \lambda_{n}\left\langle f(Q(f))-Q(f), J\left(y_{n}-Q(f)\right)\right\rangle \\
\leq & \left(1-\lambda_{n}\right)^{2}\left\|x_{n}-Q(f)\right\|^{2}+2 k \lambda_{n}\left\|x_{n}-Q(f)\right\|\left\|y_{n}-Q(f)\right\| \\
& +2 \lambda_{n}\left\langle f(Q(f))-Q(f), J\left(y_{n}-Q(f)\right)\right\rangle \\
\leq & \left(1-\lambda_{n}\right)^{2}\left\|x_{n}-Q(f)\right\|^{2}+2 k \lambda_{n}\left\|x_{n}-Q(f)\right\|^{2} \\
& +2 \lambda_{n}\left\langle f(Q(f))-Q(f), J\left(y_{n}-Q(f)\right)\right\rangle .
\end{aligned}
$$

It then follows that

$$
\begin{aligned}
\left\|x_{n+1}-Q(f)\right\|^{2} & \leq\left(1-2(1-k) \lambda_{n}+\lambda_{n}^{2}\right)\left\|x_{n}-Q(f)\right\|^{2}+2 \lambda_{n}\left\langle Q(f)-f(Q(f)), J\left(Q(f)-y_{n}\right)\right\rangle \\
& \leq\left(1-(2-k) \lambda_{n}\right)\left\|x_{n}-Q(f)\right\|^{2}+\lambda_{n}^{2} M^{2}+2 \lambda_{n}\left\langle Q(f)-f(Q(f)), J\left(Q(f)-y_{n}\right)\right\rangle,
\end{aligned}
$$

where $M=\sup _{n \geq 0}\left\|x_{n}-Q(f)\right\|$. Put

$$
\begin{aligned}
& \alpha_{n}=2(1-k) \lambda_{n} \\
& \gamma_{n}=\frac{\lambda_{n}}{2(1-k)} M^{2}+\frac{1}{1-k}\left\langle Q(f)-f(Q(f)), J\left(Q(f)-y_{n}\right)\right\rangle
\end{aligned}
$$

From the condition (C1) and Step 4, it follows that $\alpha_{n} \rightarrow 0, \sum_{n=0}^{\infty} \alpha_{n}=\infty$, and lim $\sup _{n \rightarrow \infty} \gamma_{n} \leq 0$. Since (3.29) reduces to

$$
\left\|x_{n+1}-Q(f)\right\|^{2} \leq\left(1-\alpha_{n}\right)\left\|x_{n}-Q(f)\right\|^{2}+\alpha_{n} \gamma_{n}
$$

from Lemma 2.2 with $\delta_{n}=0$, we conclude that $\lim _{n \rightarrow \infty}\left\|x_{n}-Q(f)\right\|=0$. This completes the proof.

Corollary 3.3. Let $E$ be a uniformly smooth Banach space. Let $C, T, f,\left\{\beta_{n}\right\},\left\{\lambda_{n}\right\}, f, x_{0}$, and $\left\{x_{n}\right\}$ be the same as in Theorem 3.2. Then, the conclusion of Theorem 3.2 still holds.

Proof. Since $E$ is a uniformly smooth Banach space, $E$ is reflexive and the norm is uniformly Gâteaux differentiable norm and its every nonempty weakly compact convex subset of $E$ has the fixed point property for nonexpansive mappings. Thus, the conclusion of Corollary 3.3 follows from Theorem 3.2 immediately. 
Remark 3.4. (1) If $\left\{\beta_{n}\right\}$ and $\left\{\lambda_{n}\right\}$ in Theorem 3.2 satisfy the conditions

(B2) $\sum_{n=0}^{\infty}\left|\beta_{n+1}-\beta_{n}\right|<\infty$,

(C1) $\lim _{n \rightarrow \infty} \lambda_{n}=0, \sum_{n=0}^{\infty} \lambda_{n}=\infty$,

(C2) $\sum_{n=0}^{\infty}\left|\lambda_{n+1}-\lambda_{n}\right|<\infty$, or

(C3) $\lim _{n \rightarrow \infty}\left(\lambda_{n} / \lambda_{n+1}\right)=1$, or

(C4) $\left|\lambda_{n+1}-\lambda_{n}\right| \leq \circ\left(\lambda_{n+1}\right)+\sigma_{n}, \sum_{n=0}^{\infty} \sigma_{n}<\infty$ (the perturbed control condition),

then the sequence $\left\{x_{n}\right\}$ generated by (IS) is asymptotically regular. Now, we only give the proof in case when $\left\{\beta_{n}\right\}$ and $\left\{\lambda_{n}\right\}$ satisfy the conditions (B2), (C1), and (C4). Indeed, from (IS), we have for every $n \geq 1$,

$$
\begin{gathered}
y_{n}=\lambda_{n} f\left(x_{n}\right)+\left(1-\lambda_{n}\right) T x_{n}, \\
y_{n-1}=\lambda_{n-1} f\left(x_{n-1}\right)+\left(1-\lambda_{n-1}\right) T x_{n-1},
\end{gathered}
$$

and so, for every $n \geq 1$, we have

$$
\begin{aligned}
\left\|y_{n}-y_{n-1}\right\| & =\left\|\left(1-\lambda_{n}\right)\left(T x_{n}-T x_{n-1}\right)+\lambda_{n}\left(f\left(x_{n}\right)-f\left(x_{n-1}\right)\right)+\left(\lambda_{n}-\lambda_{n-1}\right)\left(f\left(x_{n-1}\right)-T x_{n-1}\right)\right\| \\
& \leq\left(1-\lambda_{n}\right)\left\|x_{n}-x_{n-1}\right\|+L\left|\lambda_{n}-\lambda_{n-1}\right|+k \lambda_{n}\left\|x_{n}-x_{n-1}\right\| \\
& =\left(1-(1-k) \lambda_{n}\right)\left\|x_{n}-x_{n-1}\right\|+L\left|\lambda_{n}-\lambda_{n-1}\right|,
\end{aligned}
$$

where $L=\sup \left\{\left\|f\left(x_{n}\right)-T x_{n}\right\|: n \geq 0\right\}$.

On the other hand, by (IS), we also have for every $n \geq 1$,

$$
\begin{gathered}
x_{n+1}=\left(1-\beta_{n}\right) y_{n}+\beta_{n} T y_{n}, \\
x_{n}=\left(1-\beta_{n-1}\right) y_{n-1}+\beta_{n-1} T y_{n-1} .
\end{gathered}
$$

Simple calculations show that

$$
x_{n+1}-x_{n}=\left(1-\beta_{n}\right)\left(y_{n}-y_{n-1}\right)+\beta_{n}\left(T y_{n}-T y_{n-1}\right)+\left(\beta_{n}-\beta_{n-1}\right)\left(T y_{n-1}-y_{n-1}\right),
$$

then it follows that

$$
\left\|x_{n+1}-x_{n}\right\| \leq\left(1-\beta_{n}\right)\left\|y_{n}-y_{n-1}\right\|+\beta_{n}\left\|y_{n}-y_{n-1}\right\|+\left|\beta_{n}-\beta_{n-1}\right|\left\|T y_{n-1}-y_{n-1}\right\| .
$$

Substituting (3.33) into (3.36) and using the condition (C4), we derive

$$
\begin{aligned}
\left\|x_{n+1}-x_{n}\right\| & \leq\left(1-(1-k) \lambda_{n}\right)\left\|x_{n}-x_{n-1}\right\|+L\left|\lambda_{n}-\lambda_{n-1}\right|+M\left|\beta_{n}-\beta_{n-1}\right| \\
& \leq\left(1-(1-k) \lambda_{n}\right)\left\|x_{n}-x_{n-1}\right\|+L\left(\circ\left(\lambda_{n}\right)+\sigma_{n-1}\right)+M\left|\beta_{n}-\beta_{n-1}\right|,
\end{aligned}
$$

where $M=\sup \left\{\left\|T y_{n}-y_{n}\right\|: n \geq 0\right\}$. By taking $s_{n+1}=\left\|x_{n+1}-x_{n}\right\|, \alpha_{n}=(1-k) \lambda_{n}, \alpha_{n} \gamma_{n}=L \circ\left(\lambda_{n}\right)$, and $\delta_{n}=L \sigma_{n-1}+M\left|\beta_{n}-\beta_{n-1}\right|$, we have

$$
s_{n+1} \leq\left(1-\alpha_{n}\right) s_{n}+\alpha_{n} \gamma_{n}+\delta_{n}
$$


Hence, by the conditions (B2), (C1), and (C4) and Lemma 2.2, $\lim _{n \rightarrow \infty}\left\|x_{n+1}-x_{n}\right\|=0$. Moreover, from (3.33) and the condition (C4), it follows that $\lim _{n \rightarrow \infty}\left\|y_{n}-y_{n-1}\right\|=0$.

(2) The control conditions (C2) and (C3) are not comparable (coupled with condition $(C 1))$, that is, neither of them implies the others. For this fact, see [13,34]. We also refer to [13] for the examples which satisfy condition (C1) and the perturbed control condition (C4) but fail to satisfy both conditions (C2) and (C3). See also [1].

From these facts in Remark 3.4, we have the following.

Corollary 3.5. Let $E, C$, and $T$ be the same as in Theorem 3.2. Let $\left\{\beta_{n}\right\}$ and $\left\{\lambda_{n}\right\}$ be sequences in $(0,1)$ which satisfy the conditions (B1), (B2), (C1), and (C4) (or the conditions (B1), (B2), (C1), and (C2), or the conditions (B1), (B2), (C1), and (C3)), with $f \in \Sigma_{C}$ and $x_{0} \in C$ chosen arbitrarily. Let $\left\{x_{n}\right\}$ be the sequence generated by

$$
\begin{gathered}
x_{0}=x \in C, \\
y_{n}=\lambda_{n} f\left(x_{n}\right)+\left(1-\lambda_{n}\right) T x_{n}, \\
x_{n+1}=\left(1-\beta_{n}\right) y_{n}+\beta_{n} T y_{n}, \quad n \geq 0 .
\end{gathered}
$$

Then $\left\{x_{n}\right\}$ converges strongly to $Q(f) \in F(T)$, where $Q(f)$ is the unique solution of the variational inequality

$$
\langle(I-f)(Q(f)), J(Q(f)-p)\rangle \leq 0, \quad f \in \Sigma_{C}, p \in F(T)
$$

Remark 3.6. (1) Theorem 3.2 and Corollary 3.5 extend and improve the corresponding results by Moudafi [15] and $\mathrm{Xu}$ [17]. In particular, if $\beta_{n}=0$ in (IS), then Corollary 3.5 with the conditions (C1) and (C2) (or the conditions (C1) and (C3)) reduces Theorem 4.2 in the paper of $\mathrm{Xu}$ [17].

(2) Even $\beta_{n}=0$ in (IS), Corollary 3.5 generalizes the corresponding results by Halpern [2], Lions [3], Reich [4, 5], Shioji and Takahashi [6], Wittmann [7], and Xu [8] to the viscosity methods along with the perturb control condition (C4).

Next, we consider the viscosity approximation method with the weakly contractive mapping for the nonexpansive mapping.

Theorem 3.7. Let E be a reflexive Banach space with a uniformly Gateaux differentiable norm. Suppose that every weakly compact convex subset of $E$ has the fixed point property for nonexpansive mappings. Let $C$ be a nonempty closed convex subset of $E$ and $T$ nonexpansive mappings from $C$ into itself with $F(T) \neq \varnothing$. Let $\left\{\beta_{n}\right\}$ and $\left\{\lambda_{n}\right\}$ be sequences in $(0,1)$ which satisfy the conditions (B1), (B2), (C1), and (C4) (or the conditions (B1), (B2), (C1), and (C2), or the conditions (B1), (B2), (C1), and (C3)). Let $A: C \rightarrow C$ be a weakly contractive mapping and $x_{0} \in C$ chosen arbitrarily. Let $\left\{x_{n}\right\}$ be the sequence generated by

$$
\begin{gathered}
x_{0}=x \in C, \\
y_{n}=\lambda_{n} A x_{n}+\left(1-\lambda_{n}\right) T x_{n}, \\
x_{n+1}=\left(1-\beta_{n}\right) y_{n}+\beta_{n} T y_{n}, \quad n \geq 0 .
\end{gathered}
$$

Then, $\left\{x_{n}\right\}$ converges strongly to $Q\left(A x^{*}\right)=x^{*} \in F(T)$, where $Q$ is a sunny nonexpansive retraction from $C$ onto $F(T)$. 
Proof. It follows from Remark 3.1 that $F(T)$ is the sunny nonexpansive retract of $C$. Denote by $Q$ the sunny nonexpansive retraction of $C$ onto $F$. Then, $Q A$ is a weakly contractive mapping of $C$ into itself. Indeed,

$$
\|Q(A x)-Q(A y)\| \leq\|A x-A y\| \leq\|x-y\|-\psi(\|x-y\|), \quad \forall x, y \in C
$$

Lemma 2.3 assures that there exists a unique element $x^{*} \in C$ such that $x^{*}=Q\left(A x^{*}\right)$. Such an $x^{*} \in C$ is an element of $F(T)$.

Now we define an iterative scheme as follows:

$$
\begin{gathered}
z_{n}=\lambda_{n} A x^{*}+\left(1-\lambda_{n}\right) T w_{n} \\
w_{n+1}=\left(1-\beta_{n}\right) z_{n}+\beta_{n} T z_{n}, \quad n \geq 0 .
\end{gathered}
$$

Let $\left\{w_{n}\right\}$ be the sequence generated by (3.43). Then, Corollary 3.5 with $f=A x^{*}$ a constant assures that $\left\{w_{n}\right\}$ converges strongly to $Q\left(A x^{*}\right)=x^{*}$ as $n \rightarrow \infty$. For any $n$, we have

$$
\begin{aligned}
\left\|x_{n+1}-w_{n+1}\right\| & \leq\left(1-\beta_{n}\right)\left\|y_{n}-z_{n}\right\|+\beta_{n}\left\|T y_{n}-T z_{n}\right\| \\
& \leq\left\|y_{n}-z_{n}\right\| \\
& \leq \lambda_{n}\left\|A x_{n}-A x^{*}\right\|+\left(1-\lambda_{n}\right)\left\|T x_{n}-T w_{n}\right\| \\
& \leq \lambda_{n}\left(\left\|A x_{n}-A w_{n}\right\|+\left\|A w_{n}-A x^{*}\right\|\right)+\left(1-\lambda_{n}\right)\left\|x_{n}-w_{n}\right\| \\
& \leq\left\|x_{n}-y_{n}\right\|-\lambda_{n} \psi\left(\left\|x_{n}-w_{n}\right\|\right)+\lambda_{n}\left(\left\|w_{n}-x^{*}\right\|-\psi\left(\left\|w_{n}-x^{*}\right\|\right)\right) \\
& \leq\left\|x_{n}-w_{n}\right\|-\lambda_{n} \psi\left(\left\|x_{n}-w_{n}\right\|\right)+\lambda_{n}\left\|w_{n}-x^{*}\right\| .
\end{aligned}
$$

Thus, we obtain for $s_{n}=\left\|x_{n}-w_{n}\right\|$ the following recursive inequality:

$$
s_{n+1} \leq s_{n}-\lambda_{n} \psi\left(s_{n}\right)+\lambda_{n}\left\|w_{n}-x^{*}\right\|
$$

Since $\left\|w_{n}-x^{*}\right\| \rightarrow 0$, it follows from Lemma 2.4 that $\lim _{n \rightarrow \infty}\left\|x_{n}-w_{n}\right\|=0$. Hence,

$$
\lim _{n \rightarrow \infty}\left\|x_{n}-x^{*}\right\| \leq \lim _{n \rightarrow \infty}\left(\left\|x_{n}-w_{n}\right\|+\left\|w_{n}-x^{*}\right\|\right)=0
$$

This completes the proof.

Corollary 3.8. Let $E$ be a uniformly smooth Banach space. Let $C, T, A, x_{0},\left\{\beta_{n}\right\},\left\{\lambda_{n}\right\}$, and $\left\{x_{n}\right\}$ be the same as in Theorem 3.7. Then, the conclusion of Theorem 3.7 still holds.

Remark 3.9. (1) Theorem 3.7 (as well as Corollary 3.8) develops and complements the corresponding results by Cho et al. [1], Halpern [2], Lions [3], Moudafi [15], Reich [4, 5], Shioji and Takahashi [6], Wittmann [7], and $\mathrm{Xu}[8,17]$.

(2) Even $\beta_{n}=0$ in Theorem 3.7, Theorem 3.7 appears to be independent of Theorem 5.6 of Wong et al. [24] in which the control conditions (C1) and (C3) were utilized. In fact, it appears to be unknown whether a reflexive and strictly convex space satisfies the fixed point property for nonexpansive mappings. 


\section{Acknowledgments}

The author thanks the referees for their valuable comments and suggestions, which improved the presentation of this manuscript. This study was supported by research funds from Dong-A University.

\section{References}

[1] Y. J. Cho, S. M. Kang, and H. Zhou, "Some control conditions on iterative methods," Communications on Applied Nonlinear Analysis, vol. 12, no. 2, pp. 27-34, 2005.

[2] B. Halpern, "Fixed points of nonexpanding maps," Bulletin of the American Mathematical Society, vol. 73, no. 6, pp. 957-961, 1967.

[3] P.-L. Lions, "Approximation de points fixes de contractions," Comptes Rendus Hebdomadaires des Séances de l'Académie des Sciences A et B, vol. 284, no. 21, pp. 1357-1359, 1977.

[4] S. Reich, "Strong convergence theorems for resolvents of accretive operators in Banach spaces," Journal of Mathematical Analysis and Applications, vol. 75, no. 1, pp. 287-292, 1980.

[5] S. Reich, "Approximating fixed points of nonexpansive mappings," Panamerican Mathematical Journal, vol. 4, no. 2, pp. 23-28, 1994.

[6] N. Shioji and W. Takahashi, "Strong convergence of approximated sequences for nonexpansive mappings in Banach spaces," Proceedings of the American Mathematical Society, vol. 125, no. 12, pp. 3641-3645, 1997.

[7] R. Wittmann, "Approximation of fixed points of nonexpansive mappings," Archiv der Mathematik, vol. 58, no. 5, pp. 486-491, 1992.

[8] H. K. Xu, "Iterative algorithms for nonlinear operators," Journal of the London Mathematical Society, vol. 66, no. 1, pp. 240-256, 2002.

[9] H. H. Bauschke, "The approximation of fixed points of compositions of nonexpansive mappings in Hilbert space," Journal of Mathematical Analysis and Applications, vol. 202, no. 1, pp. 150-159, 1996.

[10] L. C. Ceng, P. Cubiotti, and J.-C. Yao, "Strong convergence theorems for finitely many nonexpansive mappings and applications," Nonlinear Analysis: Theory, Methods \& Applications, vol. 67, no. 5, pp. 1464-1473, 2007.

[11] L. C. Ceng, P. Cubiotti, and J.-C. Yao, "Approximation of common fixed points of families of nonexpansive mappings," Taiwanese Journal of Mathematics, vol. 12, no. 2, 2008.

[12] J. S. Jung, "Iterative approaches to common fixed points of nonexpansive mappings in Banach spaces," Journal of Mathematical Analysis and Applications, vol. 302, no. 2, pp. 509-520, 2005.

[13] J. S. Jung, Y. J. Cho, and R. P. Agarwal, "Iterative schemes with some control conditions for a family of finite nonexpansive mappings in Banach spaces," Fixed Point Theory and Applications, vol. 2005, no. 2, pp. 125-135, 2005.

[14] J. S. Jung and T. H. Kim, "Convergence of approximate sequences for compositions of nonexpansive mappings in Banach spaces," Bulletin of the Korean Mathematical Society, vol. 34, no. 1, pp. 93-102, 1997.

[15] A. Moudafi, "Viscosity approximation methods for fixed-points problems," Journal of Mathematical Analysis and Applications, vol. 241, no. 1, pp. 46-55, 2000.

[16] P.-E. Maingé and A. Moudafi, "Strong convergence of an iterative method for hierarchical fixed-point problems," Pacific Journal of Optimization, vol. 3, no. 3, pp. 529-538, 2007.

[17] H. K. Xu, "Viscosity approximation methods for nonexpansive mappings," Journal of Mathematical Analysis and Applications, vol. 298, no. 1, pp. 279-291, 2004.

[18] J. S. Jung, "Viscosity approximation methods for a family of finite nonexpansive mappings in Banach spaces," Nonlinear Analysis: Theory, Methods \& Applications, vol. 64, no. 11, pp. 2536-2552, 2006.

[19] J. S. Jung, "Convergence theorems of iterative algorithms for a family of finite nonexpansive mappings," Taiwanese Journal of Mathematics, vol. 11, no. 3, pp. 883-902, 2007.

[20] J. S. Jung, "Iterative approximation to common fixed points of a sequence of nonexpansive mappings in Banach spaces," Journal of Computational and Applied Mathematics. In press.

[21] P.-E. Maingé, "Approximation methods for common fixed points of nonexpansive mappings in Hilbert spaces," Journal of Mathematical Analysis and Applications, vol. 325, no. 1, pp. 469-479, 2007. 
[22] A. Petruşela and J.-C. Yao, "Viscosity approximation to common fixed points of families of nonexpansive mappings with generalized contraction mappings," Nonlinear Analysis: Theory, Methods $\mathcal{E}$ Applications. In press.

[23] W. Takahashi, "Voscosity approximation methods for countable families of nonexpansive mappings in Banach spaces," Nonlinear Analysis: Theory, Methods \& Applications. In press.

[24] N. C. Wong, D. R. Sahu, and J.-C. Yao, "Solving variational inequalities involving nonexpansive type mappings," Nonlinear Analysis: Theory, Methods \& Applications. In press.

[25] P.-E. Maingé, "Viscosity methods for zeroes of accretive operators," Journal of Approximation Theory, vol. 140, no. 2, pp. 127-140, 2006.

[26] T.-H. Kim and H. K. Xu, "Strong convergence of modified Mann iterations," Nonlinear Analysis: Theory, Methods \& Applications, vol. 61, no. 1-2, pp. 51-60, 2005.

[27] I. Cioranescu, Geometry of Banach Spaces, Duality Mappings and Nonlinear Problems, vol. 62 of Mathematics and Its Applications, Kluwer Academic Publishers, Dordrecht, The Netherlands, 1990.

[28] K. Goebel and S. Reich, Uniform Convexity, Hyperbolic Geometry and Nonexpansive Mappings, vol. 83 of Pure and Applied Mathematics, Marcel Dekker, New York, NY, USA, 1984.

[29] J. S. Jung and C. H. Morales, "The Mann process for perturbed $m$-accretive operators in Banach spaces," Nonlinear Analysis: Theory, Methods E Applications, vol. 46, no. 2, pp. 231-243, 2001.

[30] L. S. Liu, "Ishikawa and Mann iterative process with errors for nonlinear strongly accretive mappings in Banach spaces," Journal of Mathematical Analysis and Applications, vol. 194, no. 1, pp. 114-125, 1995.

[31] B. E. Rhoades, "Some theorems on weakly contractive maps," Nonlinear Analysis: Theory, Methods $\mathcal{E}$ Applications, vol. 47, no. 4, pp. 2683-2693, 2001.

[32] Ya. I. Alber and A. N. Iusem, "Extension of subgradient techniques for nonsmooth optimization in Banach spaces," Set-Valued Analysis, vol. 9, no. 4, pp. 315-335, 2001.

[33] Ya. I. Alber, S. Reich, and J.-C. Yao, "Iterative methods for solving fixed-point problems with nonselfmappings in Banach spaces," Abstract and Applied Analysis, vol. 2003, no. 4, pp. 193-216, 2003.

[34] H. K. Xu, "An iterative approach to quadratic optimization," Journal of Optimization Theory and Applications, vol. 116, no. 3, pp. 659-678, 2003. 